\title{
Pharmacologic Treatments of Cocaine Dependence
}

Michael B. Knable, D.O.

Saint Elizabeth's Hospital, Washington DC

Follow this and additional works at: https://jdc.jefferson.edu/jeffjpsychiatry

Part of the Psychiatry Commons

Let us know how access to this document benefits you

\section{Recommended Citation}

Knable, D.O., Michael B. (1989) "Pharmacologic Treatments of Cocaine Dependence," Jefferson Journal of Psychiatry. Vol. 7 : Iss. 2 , Article 4.

DOI: https://doi.org/10.29046/JJP.007.2.002

Available at: https://jdc.jefferson.edu/jeffjpsychiatry/vol7/iss2/4

This Article is brought to you for free and open access by the Jefferson Digital Commons. The Jefferson Digital Commons is a service of Thomas Jefferson University's Center for Teaching and Learning (CTL). The Commons is a showcase for Jefferson books and journals, peer-reviewed scholarly publications, unique historical collections from the University archives, and teaching tools. The Jefferson Digital Commons allows researchers and interested readers anywhere in the world to learn about and keep up to date with Jefferson scholarship. This article has been accepted for inclusion in Jefferson Journal of Psychiatry by an authorized administrator of the Jefferson Digital Commons. For more information, please contact: JeffersonDigitalCommons@jefferson.edu. 


\title{
Pharmacologic Treatments of Cocaine Dependence
}

\author{
Michael B. Knable, D.O.
}

The rapid escalation of cocaine abuse in the United States in the 1980's has generated a host of interesting hypotheses on various aspects of this problem. After a succinct discussion of epidemiologic, clinical, and neuro-pharmacologic aspects of cocaine abuse, a survey of the current literature on psychopharmacologic management of dependence is offered. While several agents have emerged as useful adjunctive treatments for abstinence syndromes it is important for the clinician to remember that there is not official approval for such treatments. Additionally, psychotherapeutic maneuvers, which remain the major tools in treatment of addicts, should not be overlooked when an experimental pharmacologic intervention is selected.

\section{INTRODUCTION}

In the last decade a dramatic change in the social patterns of cocaine use has forced the medical community to witness the devastation of a new epidemic. A "cocaine epidemic" that seems so radically different from the fashionable prevalence of cocaine use in the early part of this century has filled medical, pediatric, psychiatric and neonatal facilities and strained the limits of human and material resources.

One is encouraged, however, by the new public awareness of the problem. The federal government has begun to address the need for treatment more directly. Knowledge of the medical consequences of cocaine use is more widespread, due in part to the vicissitudes of entertainers and athletes who use cocaine. The DSM-IIIR has recognized diagnostic categories of cocaine dependence and withdrawal that draw upon recent studies of cocaine users.

An additional encouragement lies in the clear description of abstinence symptomatology. From an understanding of phenomenology emerges an attempt to alleviate symptoms through the use of medications. Medication may be a tool to help addicts tolerate withdrawal and then become engaged in the long-term psychosocial interventions that will probably be necessary for continued abstinence and improved functioning. This paper, after brief consideration of background ideas in epidemiology, clinical descriptions and pharmacology, will review medical treatments of withdrawal and dependence. 


\section{EPIDEMIOLOGY}

Recent epidemiologic studies of cocaine use have been reviewed in detail elsewhere (1-4), but a brief mention of important statistics is in order.

A 1985 National Institute of Drug Abuse, Household Survey estimated that 3 million Americans are dependent on cocaine. About 25 million Americans, including $40 \%$ of the population between ages 25 and 30 , have tried cocaine. About $5.8 \%$ of high school seniors are current users.

Admissions to publicly-funded treatment centers, emergency room visits that are cocaine related, and the number of cocaine related deaths increased approximately 15 fold between 1976 and 1986 .

\section{CLINICAL MANIFESTATIONS}

Descriptions of the effects of cocaine on the cardiovascular and nervous systems are widely available. However, understanding of cocaine's psychiatric effects has evolved in recent years. After brief mention of the interaction of cocaine with mood and thought processes, new ideas about abstinence symptoms will be presented.

Cocaine is classically described as a powerful euphoric. Use of cocaine as an antidepressant though, has not gained favor. Despite Freud's conviction (5) that cocaine was an effective therapy for depression, this has not been corroborated experimentally in 10 depressed patients at the National Institute of Mental Health (6). Furthermore, Post noticed that cocaine is not only ineffective as a treatment for depression but may also be capable of inducing dysphoria (7). $\mathrm{He}$ noticed that dysphoria associated with stimulant intoxication is similar clinically to the depressed affect that often accompanies fulminant mania, and that cocaine may potentiate sad affect in depressed patients. The time course of these events is unclear and Post may have been describing what are now understood to be withdrawal phenomena.

Psychosis is a severe psychic manifestation of cocaine use. The seminal work of Post (7) postulates a continuum of stimulant induced affective and psychotic states with the involvement of multiple neurochemical aberrations. Post has also reviewed the literature regarding stimulants as determinants of pathological behavior and seizures through a mechanism similar to electrical kindling (8). The assertion that stimulants may disrupt limbic function when used chronically, and through a kindling-like phenomenon, produce chronic affective and schizophreniform syndromes, is a powerful idea. Preliminary evidence suggests that long term stimulant abuse may cause degeneration of dopaminergic neurons and leave the patient with an irreversible deficit in mood regulation (1).

Gawin and others $(1,9)$ have produced a detailed description of symptomatology when 30 cocaine abusers were observed in abstinence. They divide abstinence into "crash," "withdrawal," and "extinction" phases. 
The crash phase follows a binge. Acute dysphoria, anxiety and craving are replaced within a few hours by hypersomnolence and hyperphagia. It is difficult to distinguish crash symptoms from major depression, but one may suspect a primary psychiatric disorder if neurovegetative symptoms persist after sleep has returned to normal and prolonged abstinence has been achieved. The craving to alleviate crash effects is discontinuous, unlike the craving seen with alcohol and opiate withdrawal.

Withdrawal symptoms include anergia, anhedonia, lack of interest and variable levels of craving. These symptoms seem to peak at 12-96 hours. Symptoms then remain in a fluctuating pattern and are generally not severe enough to be confused with major depression. Lethargy and dysphoria usually improve by $4-5$ months of abstinence.

Extinction refers to the brief, episodic return of craving for cocaine brought about by the influence of conditioned cues. Many stimuli, such as objects or circumstances formerly associated with drug use, and fantasies or dreams of drug use may spark craving. Such craving may return for many months or even years. Extinction is the removal of these conditioned cues.

Criticism of Gawin's model focuses on its naturalistic design and its neglect for recent reports of physical concomitants of a cocaine withdrawal syndrome, (muscle pains, chills, tremor) (10). This is an elegant framework for further elucidation of withdrawal phenomena, however.

\section{CO-MORBIDITY}

The relationship between psychopathology and drug abuse is controversial. Psychodynamic formulations of substance abuse pathology have been well summarized by Wurmser (11). In his view, addicts exhibit rudimentary capacity for use of symbol and fantasy, inability to defend against strong affects, a chronic searching to replace inadequate objects, self destructiveness and regressive gratification of narcissistic needs. Life's difficulties continually present a series of narcissistic injuries to addicts which are defended against by drug use.

Only two studies have evaluated cocaine abusers for DSM-III, Axis I co-morbidity and these are summarized by Gawin and Kleber (9). Affective disorders, including major depression, dysthymia and atypical depressions are found in $30 \%$ of users, with minor depressions comprising the majority of this group. Twenty percent of users are bipolar or cyclothymic, and approximately $5 \%$ may be seen as having residual attention deficit disorder.

Interestingly, $64 \%$ of cocaine users with DSM-III affective diagnoses prefer the intranasal route and have shorter "runs," suggesting a cessation of drug use when dysphoria is ameliorated (9).

Khantzian has been a major proponent for the concept of drug abuse as self medication for psychiatric disorders (12). While Post's NIMH study failed to show euphoric response to cocaine in subjects with major depression, Khantzian 
feels that patients with dysthymia or atypical depression may indeed respond to stimulants and hence the basis for his "self medication" hypothesis. Khantzian also believes cyclothymic patients self-medicate in order to reverse dysthymia and maintain stable hypomania. He also proposes that patients with attention deficits may be able to improve their function with cocaine (9). Flemenbaum (13) also was one of the first to see substance abuse as a parapsychiatric symptom in patients with affective disorders.

Studies of self-administration of cocaine in animals and humans suggest that the incredibly pleasurable "reward" provided by cocaine may produce addictive behavior in individuals not particularly predisposed by a psychiatric diagnosis. Fischman $(14,15)$ has shown that humans will self administer IV solutions of cocaine in a manner similar to animal models and has documented acute tolerance to the cardiovascular and subjective euphoric effects of cocaine. These data suggest that cocaine is indeed a powerfully addictive substance and that psychopathology is not necessarily a precursor of addiction.

\section{ABUSE OF OTHER DRUGS}

A problem which confounds treatment of cocaine users as much as psychiatric co-morbidity is the presence of multiple substances of abuse. Kleber (16) reports that $50 \%$ of cocaine users also abuse alcohol, $30 \%$ use marihuana, $8 \%$ use amphetamines, $5 \%$ use tranquilizers and $4 \%$ use opiates. Experience in inner city settings leads one to believe that polydrug abuse is the norm. A well known phenomenon amongst heavy cocaine users is the development of a need to "titrate" cocaine binges with depressant drugs. Many users turn to alcohol, tranquilizers or narcotics to enabable sleep after chronic cocaine ingestion.

Use of marijuana almost inevitably precedes cocaine use (4). Ninety-Six percent of cocaine users are former or concurrent users of marijuana and the likelihood of cocaine use increases with the lifetime frequency of marijuana use.

\section{PHARMACOLOGY}

Many of the current physiologic concepts concerning neuroadaptation to chronic cocaine abuse and the production of an abstinence syndrome have their basis in early models of intracranial self-stimulation. It has been known for nearly thirty five years that animals will self administer electrical stimuli to "pleasure centers" of the brain (17). The electrical stimuli are hypothesized to activate certain neurotransmitter mediated "reward pathways." It has also been found that animals will self administer central nervous system stimulants, especially when they are applied directly to reward pathways. Humans also self administer cocaine in laboratory studies (18). Stimulant self administration is probably mediated largely by mesocortical and mesolimbic dopaminergic projections. 
Controversy arises when one tries to determine exactly which transmitters or which element of transmitter chemistry is affected by chronic stimulant abuse and is therefore responsible for the neuroadaptation of addiction. Cocaine and other stimulants cause neuronal release of norepinephrine, dopamine, and possibly acetylcholine and serotonin. The re-uptake of these amines is also blocked by cocaine. Supersensitivity of $\beta$-adrenergic, $\alpha$-adrenergic and dopaminergic receptors occurs with prolonged cocaine administration. Beta-receptor supersensitivity is thought to contribute to depressive affect states, and this may account for post-cocaine dysphoria.

The most compelling neurochemical explanations for cocaine induced euphoria and post-cocaine dysphoria implicate dopamine. A recent study proposes that dopamine re-uptake inhibition is the principal determinant of dependence (19). Lesions produced in tegmental dopaminergic areas with 6hydroxydopamine decrease self administration of cocaine (20). Pimozide (a dopamine receptor blocker), but not phentolamine or phenoxybenzamine (noradrenergic blockers), blocks self administration of cocaine (21). The ability of rats to discriminate for cocaine is attenuated by pimozide, haloperidol and chlorpromazine, but this effect is not observed with propranolol, phenoxybenzamine, $\alpha$-methyl-para-tyrosine, or physostigmine (22). It is also well known that neuroleptics block amphetamine induced psychotic symptomatology in humans (23). Reports that cocaine users develop hyperprolactinemia may indicate a chronic depletion of dopamine (24). Some chronic cocaine users have also been observed to develop "pseudoparkinsonism" (25). Preliminary PET scan data from cocaine addicts demonstrate disordered DOPA utilization in the striatum when 18-fluoro-DOPA is used as a tracer (26). Though this evidence seems to favor an hypothesis of dopamine hypofunction or depletion, it must be remembered that the evidence is not conclusive, and one must not be tempted to readily accept the "one transmitter-one disease" model (27).

Cocaine's addictive potential also depends on the pharmacologic properties of the different forms of abused cocaine. Intranasal, freebased and intravenous cocaine are the patterns of use most commonly encountered, and there are significant pharmacologic differences between them (28).

Intranasal cocaine $\mathrm{HCl}$ requires 3-5 minutes for onset of action and has a mean half life of about one hour. Users commonly repeat the dose every 15-20 minutes to maintain a high.

Intravenous cocaine $\mathrm{HCl}$ produces a "rush" in $30-45$ seconds and has a half life of 10-20 minutes. The quick onset of action and shorter half life increase the addictive potential. Since the user must administer doses more frequently, in ever increasing amounts, tolerance is achieved more rapidly than with intranasal use.

Freebase cocaine is a basic salt of cocaine. Basic forms of cocaine are preferred for cocaine smoking because they have a lower temperature of volatilization and are more lipid soluble than the $\mathrm{HCl}$ salt. "Crack" is a form of 
cocaine base which has been extracted with sodium bicarbonate. When basic cocaine is smoked it is absorbed very efficiently by the pulmonary vasculature. A rush is obtained in 8-10 seconds and the high remains for only 5-10 minutes. Hence, crack's reputation as the most addictive form of cocaine.

\section{PHARMACOTHERAPIES OF COCAINE DEPENDENCE}

The ultimate goal of pharmacologic treatments is to obtain long term abstinence. Abstinence in itself may be a measurable effect from pharmacologic treatments. However, medications may also block the acute euphoric effects of cocaine, and may be effective remedies for withdrawal symptomatology. Blocked euphoria and improved withdrawal symptoms are variables that medications may affect and thereby facilitate abstinence. Several different agents have been studied for these effects.

\section{ANTIDEPRESSANTS}

Because chronic cocaine abuse has been associated with increased $\beta$ adrenergic, $\alpha$-adrenergic and dopaminergic receptor sensitivity, antidepressants have been suggested as a therapy for cocaine withdrawal. The rationale for this choice lies in the ability of antidepressants to induce $\beta$-adrenergic receptor subsensitivity after a period of time corresponding to clinical improvement of depressed affect. Antidepressants have been evaluated as agents for: blockade of acute, cocaine induced euphoria, for reduction of withdrawal associated anhedonia, dysphoria and craving, and for effectors of prolonged abstinence.

Tennant and Rawson (29) reported an open trial of low dose desipramine in 14 cocaine and 8 amphetamine abusers. They felt that cocaine abstinence was improved (5 patients relapsed within 45 days of admission) and that dysphoria, craving, and sleep disturbance were reduced. Three of 22 subjects reported that desipramine blocked the effects of cocaine or amphetamine. They based their selection of desipramine on its ability to increase synaptic norepinephrine, which may be depleted in chronic cocaine use, and not the drug's ability to decrease $\beta$ receptor sensitivity. Hence their trial lasted only seven days.

Rosecan (30) reported substantial reduction in cocaine use in $80 \%$ of subjects with therapeutic doses of imipramine (100-300 mgs./day). Rosecan also administered $1000 \mathrm{mg}$. of tyrosine in the morning and $1000 \mathrm{mg}$. of tryptophan at bedtime, and anecdotally observed that acute euphoria was blocked and that withdrawal associated craving was diminished.

Gawin and Kleber (31) conducted an open trial of desipramine in therapeutic doses (200 mg./day) in six users who had failed to stop cocaine use with psychotherapy alone. All subjects eventually became abstinent and quantitative measures of craving were reduced by the third week of treatment. Decreased craving occurred in subjects regardless of coexisting psychiatric diagnosis. 
These authors report a second trial of 26 patients without affective disorder who had failed to become abstinent after four weeks of psychotherapy and were treated with desipramine, lithium, methylphenidate or psychotherapy (32). Eighty percent of subjects with depressive symptoms who were treated with desipramine were abstinent for four weeks after nine weeks of drug treatment. Psychotherapy produced abstinence in $35 \%$. No lithium responders were noted and methylphenidate was discontinued because patients tended to exhibit increased craving after 2 weeks of treatment.

Rowbotham et al (33) performed a well controlled study evaluating the possibility that serotonergic re-uptake blockade by an antidepressant may block acute euphoria with cocaine. They also postulated that antidepressants affecting serotonergic uptake may be safer in cocaine abusers since norepinephrine reuptake blockade by antidepressants and cocaine together may be synergistic and dangerous. When subjects were pretreated with $100 \mathrm{mg}$. of trazodone, a 2 $\mathrm{mg} . / \mathrm{kg}$. dose of cocaine still produced euphoria although the sympathomimetic effects of cocaine were diminished.

One case report exists of $200 \mathrm{mg}$./day of trazodone producing rapid improvement in withdrawal symptoms and effecting abstinence of 11 months. The authors suggest that trazodone's lack of anticholinergic effects that could potentiate the sympathomimetic effects of cocaine may make trazodone a more acceptable treatment than standard tricyclic antidepressants (34).

Baxter (35) reported two cases in which dysphoria and hypersomnolence after the abrupt cessation of cocaine use were improved within 1-2 days after initiation of desipramine treatment.

Giannini et al divided 20 cocaine abusers into those treated with 150 $\mathrm{mg}$./day of desipramine and those receiving $25 \mathrm{mg}$./day of diphenhydramine as placebo. They used the Hamilton Depression Rating Scale and clinical indices to assess symptomatology and found that the placebo group developed significant depression between days 0 and 20 of abstinence. Desipramine significantly reduced depression between days 20 and 40 (36).

Gawin (32) has reported an ongoing double blind study comparing desipramine, lithium and placebo in 75 cocaine abusers. Data have been collected on 24 patients and reveal significant decreases in cocaine use and in craving from four weeks after initiation of desipramine treatment. Plasma levels were also monitored weekly and seem to suggest that cocaine addicts may require higher plasma levels than depressed subjects.

\section{LITHIUM}

Work in the 1970's demonstrated that the behavioral manifestations of amphetamines and cocaine could be attenuated in laboratory animals with lithium treatment (37).

Angrist and Gershon (36) selected 8 patients with diverse psychiatric problems from an inpatient unit, and after stabilization, assessed the effects of 0.5 
$\mathrm{mg}$./kg. of d-amphetamine on subjects before and after treatment with lithium. They felt the attenuation of behavioral amphetamine effects was variable but that the pressor response of amphetamine was attenuated uniformly.

Amphetamine abuse was spontaneously discontinued in 2 patients who could not experience euphoria from amphetamines while receiving lithium (39). Cronson and Flemenbaum reported 5 anecdotal cases in which cocaine induced euphoria was prevented by lithium treatment (40).

Scott and Mullaly reported on 2 heavy cocaine users who had developed chronic refractory psychoses and were successfully treated with lithium (41). A third patient with psychotic depression also improved and denied euphoric effects of cocaine while taking lithium.

Gawin and Kleber, in their open trial, found four of five cyclothymic patients treated with lithium to be abstinent at three months (31). Patients with DSM-III diagnoses of depression or dysthymia did not improve with lithium, and lithium did not appear to block cocaine induced euphoria.

Gawin and Kleber (32) in their ongoing double blind study have found that lithium reduces craving rapidly and for about one week. Craving and use of cocaine appeared to increase to baseline levels after this period.

\section{BROMOCRIPTINE, AMANTADINE, L-DOPA}

Because cocaine acutely increases synaptic release of dopamine, blocks the re-uptake of dopamine, and may chronically lead to a dopamine depletion state, drugs affecting dopaminergic systems have begun to be studied. Bromocriptine is an ergot derivative that has agonistic effects at dopamine receptors in various brain sites. Amantadine releases dopamine and norepinephrine from neuronal storage sites and slows re-uptake of dopamine and norepinephrine.

A small double blind study comparing placebo to a single dose of bromocriptine $(0.625 \mathrm{mg}$.) in two cocaine abusers with dysphoria and intense craving resulted in marked improvement in self rating of craving with bromocriptine in six repeated trials (42).

An anecdotal report on 7 users with DSM-III diagnoses of cocaine abuse and attention deficit disorder (ADD) found global improvement of attention and craving when bromocriptine was begun at $0.625 \mathrm{mg}$. t.i.d., and increased to a range of $7.5-12.5 \mathrm{mg}$./day. These patients were abstinent during follow-up periods ranging from 3 to 9 months (43).

Tennant and Sagherian (44) performed a double blind study of 14 users comparing bromocriptine (5.0-7.5 mg./day) with amantadine (100-300 mg./ day). Only one subject treated with bromocriptine was able to complete ten days of treatment due to side effects. The subjective improvements in craving and dysphoria were similar for bromocriptine and amantadine. However, the "mean daily withdrawal score" indicated better performance with amantadine. These patients also received daily doses of tyrosine and tryptophan, and though this would not confound differences between bromocriptine and amantadine, these 
amino acids may provide some palliative effect in themselves. Bromocriptine was also reported to block cocaine induced euphoria, and the authors postulate that bromocriptine may be well suited to treatment of patients who require partial agonist/antagonist therapy similar to naltrexone. They also felt that amantadine was safer and more effective in an ambulatory setting.

Giannini et al (45) performed a double-blind study for six weeks comparing bromocriptine to placebo in 24 cocaine addicts. Patients receiving bromocriptine $(0.625 \mathrm{mg}$ q.i.d.) had significant improvements on the Brief Psychiatric Rating Scale when compared to placebo. The authors conclude that bromocriptine is an effective and fast acting treatment for withdrawal.

An open trial of $10 \mathrm{mg}$. carbidopa and $100 \mathrm{mg}$. L-dopa (b.i.d. or t.i.d.) for 1-2 weeks in "several" cocaine abusers resulted in "some response" in an attempt to alleviate withdrawal symptoms (46).

\section{STIMULANTS}

Stimulants such as methylphenidate are pharmacologically similar to cocaine and share cross tolerance with cocaine. Khantzian (47) described a heavy cocaine user successfully treated with methylphenidate $15 \mathrm{mg}$. t.i.d. and postulated a residual ADD leading to self medication with cocaine.

A second report (48) of three patients also meeting some criteria for ADD further supported the self medication hypothesis. Patients showed improvement in withdrawal symptoms.

Methylphenidate was not effective in producing cocaine abstinence in five abusers without ADD symptomatology despite 2-5 week trials in dosages up to $100 \mathrm{mg}$. daily (49).

Magnesium pemoline in doses of $75-225 \mathrm{mg}$./day was reported to be effective in 2 patients with presumed residual ADD. These patients experienced improvements in withdrawal symptoms and in long term abstinence (50).

Gawin (32) has reported that methylphenidate actually increases cocaine craving after a 1-2 week period of treatment in patients without ADD and proposes that a mild euphoria associated with methylphenidate use acts as a conditioned cue to resume cocaine use. The possibility of toxic interactions between stimulants and cocaine has not been evaluated fully and this must be kept in mind, especially in patients likely to abuse stimulants as well as cocaine.

\section{TYROSINE}

Based on the hypothesis that cocaine depletes catecholamines and that tyrosine may increase the synthesis of dopamine, norepinephrine and epinephrine, Gold et al (51) administered $0.1 \mathrm{mg} / \mathrm{kg}$. of tyrosine to 6 addicts undergoing withdrawal. Tyrosine had "consistent anti-withdrawal effects" in an unspecified period of time. These data are interesting and merit further investigation since the relative innocuousness and low abuse potential of tyrosine are attractive. 


\section{SUMMARY OF DRUG THERAPIES}

Three antidepressants, desipramine, imipramine and trazodone, have been studied for their effects on cocaine addicts.

Desipramine is mentioned as an agent capable of producing abstinence in 3 uncontrolled and 1 controlled study. The length of abstinence varies from one to many months.

Desipramine improved withdrawal symptomatology, including dysphoria and craving, in 2 controlled and 3 uncontrolled studies. Desipramine seemed to help immediately in 2 studies, but required 2-4 weeks for effectiveness in the remainder.

One uncontrolled study states that desipramine blocks acute euphoria associated with cocaine ingestion.

Imipramine, in one uncontrolled study, was found to be an effective agent for abstinence, withdrawal symptomatology and inhibition of acute euphoria.

Trazodone was found to be effective in the treatment of withdrawal symptoms and in maintaining abstinence in one uncontrolled paper. One controlled study found that trazodone did not block acute euphoria.

Lithium was found to be an effector of abstinence when restricted to cyclothymic patients in one uncontrolled study. In one controlled study lithium was felt to have a transient effect on abstinence.

One controlled study found lithium to have a brief, palliative effect on withdrawal symptoms (for about one week).

Three uncontrolled reports found that lithium is an inhibitor of cocaine induced euphoria. One uncontrolled study found this effect to be lacking.

One case report has found lithium to be an effective treatment for prolonged psychosis and/or psychotic depression following heavy, chronic cocaine use.

Bromocriptine, in three controlled studies and in one uncontrolled study, seems to alleviate dysphoria and craving. It seems to exert this effect rapidly but is often associated with unpleasant side effects.

Bromocriptine is reported to have helped achieve abstinence in one uncontrolled and in one controlled study.

In one uncontrolled report bromocriptine was felt to block cocaine-induced euphoria.

Amantadine was found to improve withdrawal symptoms in one controlled study.

L-dopa was found helpful in treating withdrawal symptoms in one case report.

Stimulants have been reported as effective treatments for withdrawal in two uncontrolled studies. However, one uncontrolled and one controlled study found that stimulants may worsen withdrawal symptoms. 
Two uncontrolled reports cite stimulants as helpful in obtaining abstinence. Many of the studies involving stimulants were performed on patients with presumptive, premorbid diagnoses of attention deficit disorder.

\section{CONCLUSION}

This review has presented issues in epidemiologic, clinical and neuropharmacologic aspects of cocaine abuse. Further research into these areas can be expected to highlight several questions. Further elucidation of a cocaine withdrawal syndrome in large cohorts, utilizing full descriptive and physiologic measures may more clearly define "subsyndromes" that would respond favorably to tailored forms of therapy. Long term prospective studies evaluating the presence of pre-existent psychiatric diagnoses are necessary. The attempt to relate animal models to the neurophysiology of addictive behaviors in humans is a very murky area which under-scores the traditional gulf between descriptive and pathophysiologic knowledge in psychiatry. Anatomic evidence for dopamine depletion in the brain is still lacking, but presumptive evidence would suggest its presence in cocaine abusers.

The psychopharmacologic management of cocaine dependence is a young and developing field. Current studies are quite preliminary; for the most part anecdotal and involve small numbers of patients. Since most reports are favorable, one is tempted to consider pharmacotherapy as an attractive adjunct to psychotherapy. Perhaps, with the alleviation of withdrawal symptoms, patients are made more "available" for psychotherapeutic work.

From the work that is currently available it would seem that lithium, dopaminergic agonists, and, possibly, in a proportion of addicts with premorbid attention deficits, stimulants, act rather quickly to improve craving and dysphoria during cocaine withdrawal. Perhaps these agents will be seen as especially useful for the acute, inpatient management of withdrawal. One is also hopeful that antidepressant therapy may emerge as an especially useful tool for treating the long term feelings of dysphoria and craving that so often preclude long term abstinence.

\section{REFERENCES}

1. Gawin FH, Ellinwood EH: Cocaine and other stimulants: Actions, abuse and treatment. New England Journal of Medicine 318(18):1173-82, 1988

2. Kleber HD: Introduction, cocaine abuse: Historical, epidemiologic, and psychologic perspectives. J Clin Psychiatry 49(2):3-6, 1988

3. Herridge P, Gold M: The new user of cocaine: Evidence from 800-COCAINE. Psychiatric Annals 18(9):521-22, 1988

4. Adams EH, Gfoerer J: Elevated risk of cocaine use in adults. Psychiatric Annals 18(9):523-27, 1988 
5. Jones E: The cocaine episode in The Life \& Work of Sigmund Freud. Edited by Trilling L, Marcus S. New York, Basic Books, pp 52-67, 1953

6. Post RM, et al: Effects of cocaine in depressed patients. American Journal of Psychiatry 131(3):511-517, 1974

7. Post RM: Cocaine psychoses: A continuum model. American Journal of Psychiatry 132(3):225-231, 1975

8. Post RM, Kipanda RT: Cocaine, kindling, and psychosis. American Journal of Psychiatry 133(6):627-632, 1976

9. Gawin FH, Kleber HD: Abstinence symptomatology and psychiatric diagnosis in cocaine abuse. Archives of General Psychiatry 43(2):107-113, 1986

10. Brower KJ, Paredes A: Cocaine withdrawal. Archives of General Psychiatry 44(3): 297-298, 1987

11. Wurmser L: Psychoanalytic consideration of the etiology of compulsive drug use. Journal of the American Psychoanalytic Association 22:820-843, 1974

12. Khantzian EJ, et al: Methylephenidate treatment of cocaine dependence-A preliminary report. Journal of Substance Abuse Treatment 1:107-112, 1984

13. Flemenbaum A: Affective disorders and "chemical dependence": Lithium for alcohol and drug addiction? Diseases of the Nervous System 35:281-285, 1974

14. Fischman MW, et al: Acute tolerance development to the cardiovascular and subjective effects of cocaine. Journal of Pharmacology and Experimental Therapeutics 235:667-682, 1985

15. Fischman MW, et al: Data presented at North American Conference on Cocaine Abuse and its Treatment. Washington, D.C.-September 16, 1987

16. Kleber HD: Data presented at North American Conference on Cocaine Abuse and its Treatment. Washington, D.C., September 16, 1987

17. Olds J, Milner PM: Positive reinforcement produced by electrical stimulation of the septal area and other regions of rat brain. Comprehensive Physiology \& Psychology 47:419-427, 1954

18. Fischman MW, Schuster CR: Cocaine self administration in humans. Fed Proc 41:241-246, 1982

19. Ritz MC, et al: Cocaine receptors on dopamine transporters are related to self administration of cocaine. Science 237:1219-1223, 1987

20. Roberts DCS, Koob GF: Disruption of cocaine self-administration following 6hydroxydopamine lesion of the ventral tegmental area in rats. Pharmacology Biochemistry and Behavior 17:901-904, 1982

21. DeWit H, Wise RA: Blockade of cocaine reinforcement in rats with the dopamine receptor blocker pimozide, but not with the noradrenergic blockers phentolamine or phenoxybenzamine. Canadian Journal of Psychology 31(4):195-203, 1977

22. Jarbe VC: Cocaine as a discriminative cue in rats: interaction with neuroleptics and other drugs. Psychopharmacology 59:183-187, 1978

23. Angrist R, et al: The antagonism of amphetamine induced symptomatology by a neuroleptic. American Journal of Psychiatry 131(7):817-819, 1974

24. Dackis CA, et al: Hyperprolactinemia in cocaine abusers. Society of Neuroscience Abstract 10:1099, 1984

25. Dackis CA, et al.: The Physiology of cocaine craving and "crashing." Archives of General Psychiatry 44(3)298-299, 1987

26. Baxter LR: Data presented at North American Conference on Cocaine Abuse and Its Treatment. Washington, DC, September 16, 1987 
27. Kleber HD, Gawin FH: “In Reply." Archives of General Psychiatry 44(3):298, 1987

28. Vereby K \& Gold M: From coca leaves to crack, the effects of dose and route of administration in abuse liability. Psychiatric Annals 18(9):513-20, 1988

29. Tennant FS, Rawson RA: Cocaine and amphetamine dependence treated with desipramine. National Institute of Drug Abuse Research Monograph, Problems of Drug Dependence. Harris, LS, editor. 43:351-355, 1983

30. Rosecan JS: The psychopharmacologic treatment of cocaine addiction (abstract). VII World Congress of Psychiatry. Vienna-July 11-16th, 1983

31. Gawin FM, Kleber HD: Cocaine abuse treatment, open pilot trial with desipramine and lithium carbonate. Archives of General Psychiatry 41:903-909, 1984

32. Gawin FH: Data presented at North American Conference on Cocaine Abuse and its Treatment. Washington, D.C., September 16, 1987

33. Rowbotham MC: Trazodone-oral cocaine interactions. Archives General Psychiatry 41:895-899, 1984

34. Small GW, and Purcell JJ: Trazodone and cocaine abuse. Archives General Psychiatry 42:524, 1985

35. Baxter LR: Desipramine in the treatment of hypersomnolence following abrupt cessation of cocaine use. American Journal of Psychiatry 140(11):1525-26, 1983

36. Giannini AJ, et al: Treatment of depression in chronic cocaine and PCP abuse with desipramine. Journal of Clinical Pharmacology 26:211-214, 1986

37. Flemenbaum A: Antagonism of behavioral effects of cocaine by lithium. Pharmacology, Biochemistry and Behavior 7:83-85, 1977

38. Angrist B, and Gershon S: Variable attenuation of amphetamine effects by lithium. American Journal of Psychiatry 136(6):806-810, 1979

39. Flemenbaum A: Does lithium block the effects of amphetamine? American Journal of Psychiatry 131:820-821, 1974

40. Conson AJ, and Flemenbaum A: Antagonism of cocaine highs by lithium. American Journal of Psychiatry 135:856-857, 1978

41. Scott ME, and Mullaly RW: Lithium therapy for cocaine induced psychosis. Southern Medical Journal 74:1475-1477, 1981

42. Dackis CA, and Gold MS: Bromocriptine as a treatment of cocaine abuse. Lancet I:1151-1152, 1985

43. Dackis CA et al: Bromocriptine treatment for cocaine abuse: The dopamine depletion hypothesis. International Journal of Psychiatry in Medicine 15(2):125-135, 1985-86.

44. Tennant FS, Sagherian AA: Double blind comparison of amantadine and bromocriptine for ambulatory withdrawal from cocaine dependence. Archives of Internal Medicine 147:109-112, 1987

45. Giannini AJ, et al: Bromocriptine therapy in cocaine withdrawal. J Clin Psychopharmacology 27:267-70, 1987

46. Rosen $\mathrm{H}$, et al: Clinical trial of carbidopa L-DOPA combination for cocaine abuse. American Journal of Psychiatry 143(11):1493, 1986

47. Khantzian EJ: An extreme case of cocaine dependence and marked improvement with methylphenidate treatment. American Journal of Psychiatry 140(6):784-785, 1983

48. Khantzian EJ, et al: Methylphenidate treatment of cocaine dependence: A preliminary report. J Subs Abuse Treatment 1:107-12, 1984 
49. Gawin FH, et al: Methylphenidate treatment of cocaine abusers without attention deficit disorder: A negative report. American Journal of Drug and Alcohol Abuse 11(3 \& 4): 193-197, 1985

50. Weiss RD, et al: Treatment of chronic cocaine abuse and attention deficit disorder, residual type, with magnesium pemoline. Drug and Alcohol Dependence 15:69-72, 1985

51. Gold MS, et al: Cocaine withdrawal: Efficacy of tyrosine. Society of Neuroscience Abstract 9:157, 1983 